\title{
Rancang Bangun Sistem Pegontrolan Temperatur dan Waktu untuk Proses Heat Treatmet
}

\author{
Sari Widya Fitri", Harmadi, Wildian \\ Jurusan Fisika FMIPA Universitas Andalas \\ Kampus Unand, Limau Manis, Padang, 25163 \\ *Sari.wifi93@gmail.com
}

\begin{abstract}
ABSTRAK
Telah dirancang sistem pengontrolan temperatur dan waktu otomatis menggunakan sensor termokopel tipe-k untuk proses heat treatment. Proses heat treatment dipengaruhi oleh beberapa parameter diantaranya temperatur, laju pemanasan, dan waktu tahan (holding time). Pengaturan temperatur dan laju pemanasan dilakukan dengan mengatur daya elemen pemanas menggunakan rangkaian driver optotriac (TRIAC BT139 dan optocoupler MOC3021). Pengontrolan waktu tahan dilakukan dengan menggunakan timer sebagai pencacah waktu digital. Temperatur dan waktu sistem diatur user melalui keypad 4x4 sebagai setpoint kemudian data ditampilkan pada LCD karakter 2x16. Pada penelitian ini dilakukan pengujian sensitivitas sensor, pengujian temperatur maksimum dan waktu tahan maksimum sistem. Hasil pengujian menunjukkan bahwa tegangan keluaran sensor termokopel tipe-k sebanding dengan temperatur dengan sensitivitas $0.041 \mathrm{mV} /{ }^{\circ} \mathrm{C}$. Temperatur maksimum sistem pengontrolan heat treatment adalah sebesar $188^{\circ} \mathrm{C}$ dengan waktu tahan maksimum 5 jam.

Kata kunci: heat treatment, holding time, optotriac, termokopel tipe-k
\end{abstract}

\begin{abstract}
Automatic temperature and time control system has been designed using thermocouple type-k sensor for heat treatment process. The heat treatment process is influenced by several parameters such as temperature, heating rate, and holding time. The temperature setting and heating rate are performed by adjusting the heating element power using optotriac driver circuit (TRIAC BT139 and optocoupler MOC3021). Endurance time control is performed using a timer as a digital timer counter. Temperature and system time is set by user through $4 x 4$ keypad as setpoint then data is displayed on $2 x 16$ character $L C D$. In this research, sensitivity sensor, maximum temperature and maximum system resistance are tested. The test results show that the output voltage of the k-type thermocouple sensor is proportional to the temperature with a sensitivity of $0.041 \mathrm{mV} / \mathrm{oC}$. The maximum temperature of heat treatment control system is 188 oC with maximum holding time of 5 hours.

Keywords: heat treatment, holding time, optotriac, thermocouple type-k
\end{abstract}

\section{PENDAHULUAN}

Heat treatment adalah proses perlakuan panas pada suatu material sampai temperatur tertentu dan ditahan selama selang beberapa waktu (holding time). Perlakuan ini memerlukan pemanasan untuk mengubah sifat fisik material khususnya struktur mikronya, sehingga diperoleh penguatan (pengerasan) maupun pelunakan dari material tersebut dengan atau tanpa merubah komposisinya (Raharjo dan Kusharjanta, 2013). Perubahan struktur mikro bertujuan untuk menghasilkan sifat-sifat logam sesuai dengan yang diinginkan secara keseluruhan maupun sebagian. Heat treatment juga dapat dimanfaatkan untuk merekayasa sifat mekanik suatu material menjadi lebih baik dengan memvariasikan temperatur dan waktu perlakuan (Kurniawan, 2014). Proses heat treatment sangat diperlukan dalam penelitian bidang material di laboratorium.

Alat heat treatment yang umumnya digunakan di laboratorium diantaranya furnace dan oven listrik. Sistem pengontrolan temperatur dan waktu kedua alat ini masih dikerjakan secara manual. Pada dasarnya alat heat treatment otomatis telah tersedia di pasaran namun alat ini umumnya dalam skala industri dengan harga yang relatif mahal sehingga untuk penelitian skala laboratorium masih digunakan alat manual yang menyebabkan hasil penelitian menjadi kurang optimal. Permasalahan ini dapat diatasi dengan merancang sendiri alat heat treatment yang dibutuhkan dengan biaya yang lebih terjangkau.

Sistem instrumentasi untuk heat treatment dengan sistem kontrol temperatur dan waktu telah banyak dikembangkan oleh peneliti sebelumnya yaitu Kingsley, dkk. (2012) yang mengembangkan low heat treatment pada furnace. Suprastiyo dan Tjahjanti (2016) membuat 
electric furnace berbasis mikrokontroler. Hasil penelitian masih membutuhkan daya yang cukup besar sehingga kurang efisien dalam penggunaan. Peneliti lain Suari (2011) merancang sistem pewaktuan dan pengontrolan temperatur pada kamar temperatur menggunakan sensor LM35DZ. Kelemahan sistem ini adalah kecilnya rentang temperatur yang dapat diatur yaitu mulai dari temperatur kamar sampai $99{ }^{\circ} \mathrm{C}$. Selain itu pengontrolan temperatur masih bersifat analog dengan menggunakan relay.

Berdasarkan permasalahan di atas, maka pada penelitian ini dilakukan perancangan sistem kontrol temperatur sederhana yang dapat bekerja secara otomatis dan digital sesuai input user untuk proses heat treatment. Sistem kontrol temperatur diintegrasikan dengan waktu untuk pengaturan holding time pada proses perlakuan. Pengontrolan temperatur menggunakan sensor termokopel tipe-k dan driver optotriac untuk mengatur laju pemanasan.

\section{METODE}

Perancangan sistem terdiri dari perancangan perangkat keras dan perangkat lunak alat heat treatment. Diagram blok perancangan sistem dapat dilihat pada Gambar 1. Sistem pengontrolan temperatur pada penelitian ini dilakukan secara digital dan otomatis. Temperatur sistem akan diindera oleh sensor temperatur termokopel tipe-k. Pengontrolan diawali dengan masuknya input data dari user (berupa pengaturan temperatur dan waktu) melalui keypad oleh mikrokontroler. Selanjutnya mikrokontroler membandingkan data masukan temperatur dengan temperatur sistem yang telah terdeteksi oleh sensor termokopel tipe-k. Agar nilai temperatur berada pada range batas input maka digunakan rangkaian optotriac untuk mengontrol daya pada elemen pemanas selama waktu input. Data temperatur dan waktu ditampilkan di LCD.

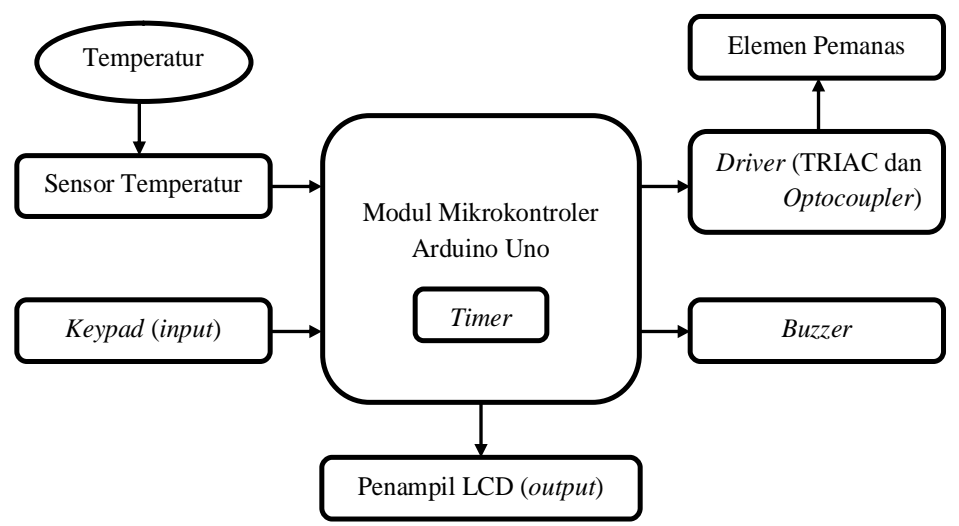

Gambar 1 Diagram blok sistem

\subsection{Rancang bangun perangkat keras}

Perancangan perangkat keras dibuat dalam blok-blok rangkaian terpisah untuk memudahkan analisis kesalahan.

\subsubsection{Perancangan rangkaian sensor termokopel tipe-k}

Rangkaian sensor termokopel diperlukan untuk mengaktifkan sensor agar dapat mengindera temperatur suatu sistem. Tegangan keluaran sensor termokopel ini cukup kecil sehingga jika langsung dihubungkan dengan $\mathrm{ADC}$ maka hanya dapat mengubah data untuk setiap kenaikan temperatur dengan rentang yang kecil yaitu $\pm 0,041 \mathrm{mV} /{ }^{\circ} \mathrm{C}$. Tegangan keluaran sensor diperkuat dengan IC MAX6675 yang juga berfungsi sebagai pengkonversi sinyal keluaran sensor dari analog menjadi data digital. Termokopel yang dirangkai dengan IC MAX6675 hanya dapat bekerja pada rentang temperatur $0{ }^{\circ} \mathrm{C}$ sampai $1024{ }^{\circ} \mathrm{C}$.

\subsubsection{Perancangan rangkaian driver pengontrolan elemen pemanas}

Elemen pemanas yang digunakan adalah sebuah heater 400 watt. Pengontrolan elemen pemanas ini menggunakan rangkaian optotriac sebagai rangkaian driver elemen pemanas. Rangkaian pengontrolan elemen pemanas dapat dilihat pada Gambar 2. Rangkaian optotriac terdiri dari komponen optocoupler jenis MOC3021 dan TRIAC BT139 sebagai kontaktor. 
Optocoupler berfungsi sebagai isolasi antar rangkaian pengolah sinyal DC dengan rangkaian pengolah sinyal AC, sedangkan TRIAC berfungsi sebagai sakelar elektrik tegangan AC untuk mengaktifkan elemen pemanas dengan memberikan picuan. Sinyal picuan melalui program akan mengalirkan arus ke dalam komponen LED dari MOC3021 dan menghasilkan cahaya. Cahaya ini kemudian diterima oleh fototransistor sehingga arus mengalir untuk mengaktifkan TRIAC.

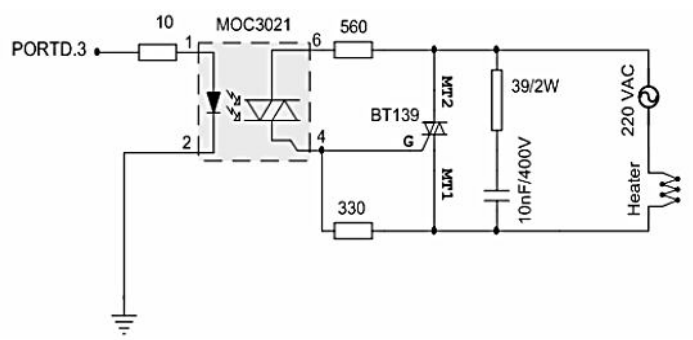

Gambar 2 Rangkaian driver optotriac

\subsection{Rancang bangun perangkat lunak}

Perancangan perangkat lunak berkaitan dengan program yang akan dimasukkan ke dalam mikrokontroler. Sebelum membuat program dibutuhkan alur penulisan program yang akan dimasukkan ke dalam mikrokontroler. Diagram alir program dapat dilihat pada Gambar 3.

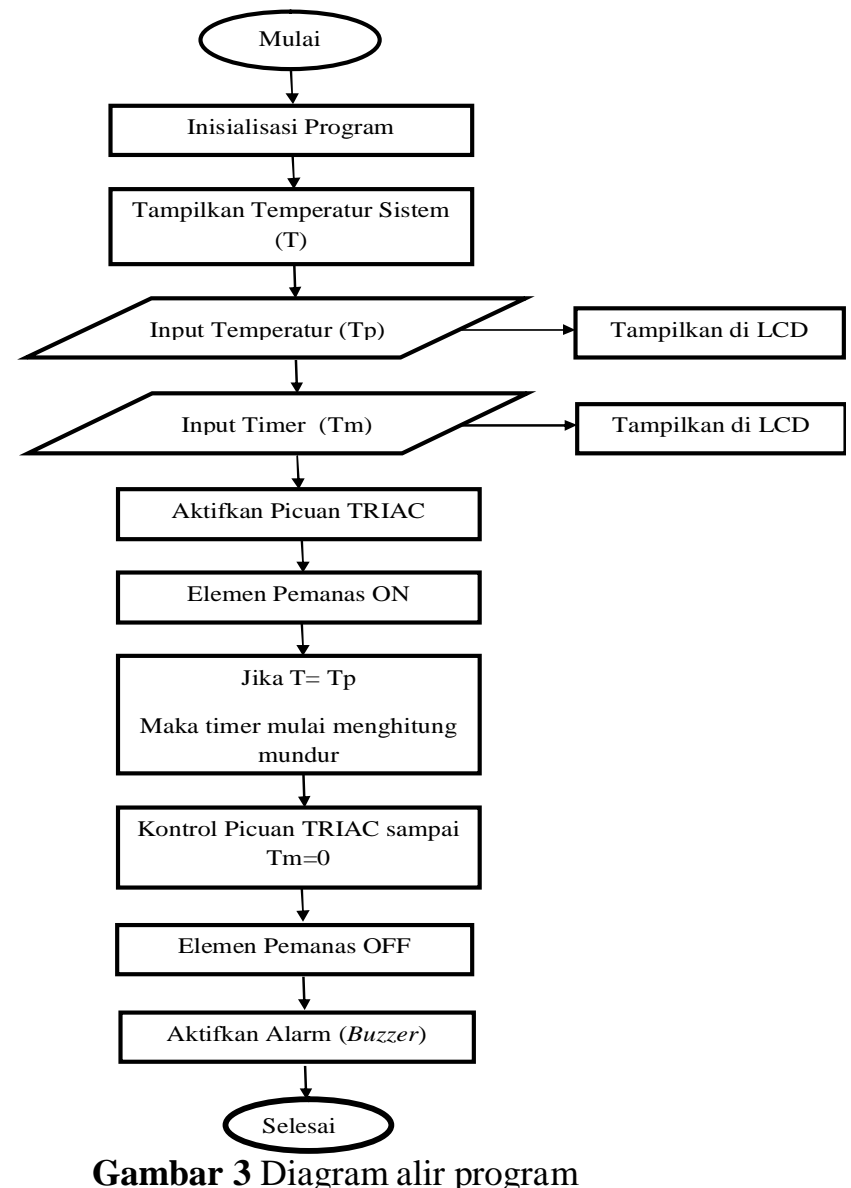

Program dimulai dengan proses inisialisasi, dimana LCD akan menampilkan temperatur sistem $(T)$ yang terdeteksi oleh sensor termokopel. Langkah selanjutnya adalah memasukan data temperatur $(T p)$ dan waktu tahan $(T m)$. Setelah input dimasukkan maka picuan TRIAC akan aktif dan elemen pemanas akan menyala sampai $(T=T p)$. Kemudian sistem pengontrolan input digital optocoupler akan mengkonversi picuan TRIAC untuk mempertahankan temperatur 
sampai selesai waktu tahan input. Jika $(T m=0)$, maka program akan mengaktifkan alarm dan elemen pemanas akan mati secara otomatis.

\section{HASIL DAN DISKUSI}

\subsection{Rancang bangun sistem}

Perangkat keras hasil perancangan sistem pengontrolan temperatur dan waktu untuk proses heat treatment dapat dilihat pada Gambar 4. Pengujian alat diawali dengan pengujian masing-masing blok rangkaian untuk mempermudah mencari kesalahan apabila sistem tidak berfungsi dengan baik. Pengujian selanjutnya adalah pengujian sistem alat secara keseluruhan.

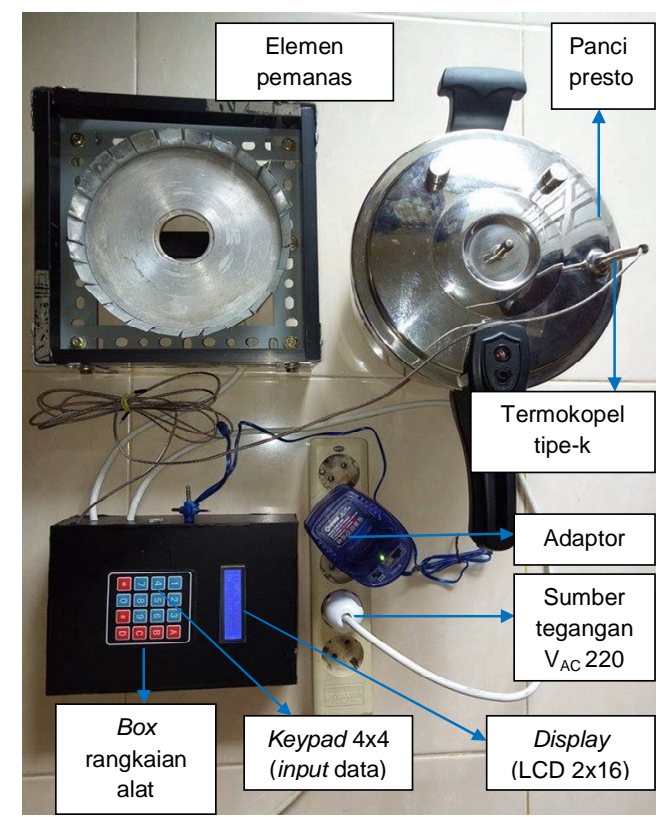

Gambar 4 Peragkat sistem secara keseluruhan

\subsection{Hasil pengujian sensitivitas sensor termokopel tipe-k}

Pengujian sensor dilakukan dengan mengukur perubahan tegangan keluaran (output) sensor terhadap kenaikan temperatur yang dihasilkan elemen pemanas berdaya 400 watt. Sensor dirangkai dengan modul IC MAX6675 kemudian dihubungkan ke board Arduino. Selanjutnya library program diupload untuk mengakses pembacaan temperatur. Pengujian ini bertujuan untuk melihat sensitivitas sensor. Hubungan antara perubahan temperatur terhadap tegangan keluaran pada sensor dapat dilihat pada Gambar 5.

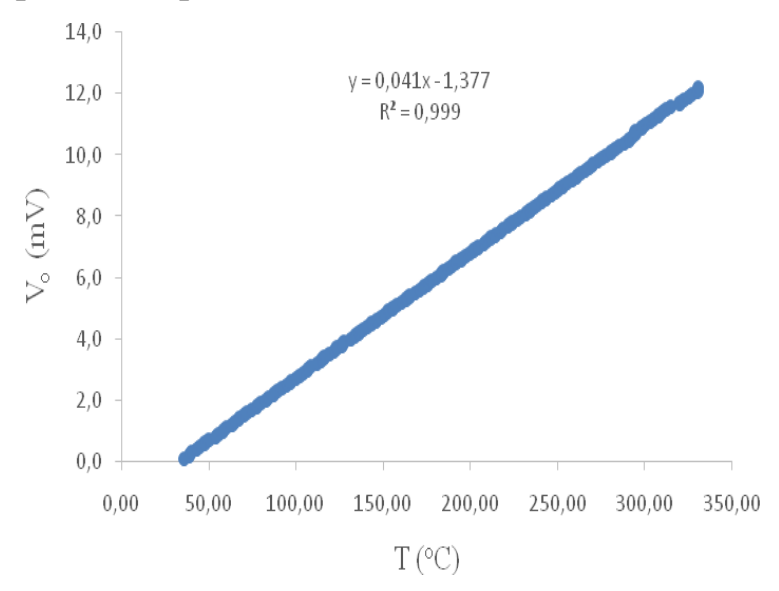

Gambar 5 Grafik hasil pegujian sensitivitas sensor termokopel tipe-k 
Berdasarkan grafik hasil pengujian didapatkan pendekatan garis linier yang menggambarkan hubungan antara temperatur dan tegangan output sensor. Pendekatan tersebut menyatakan nilai sensitivitas sensor sebesar $0,041 \mathrm{mV} /{ }^{\circ} \mathrm{C}$ dan koefisien determinasi sebesar 0,9999. Koefisien ini menunjukkan bahwa 99,9 \% tegangan keluaran sensor dipengaruhi kenaikan temperatur.

\subsection{Hasil pengujian laju pemanasan}

Pengujian ini dilakukan untuk melihat laju perubahan temperatur yang dihasilkan elemen pemanas per satuan waktu. Pengujian dilakukan dengan cara menghubungkan elemen pemanas dengan tegangan AC $220 \mathrm{~V}$ yang diukur menggunakan sensor termokopel tipe-k dan modul Arduino yang telah diuji. Hasil pengujian dapat dilihat dari grafik pada Gambar 6.

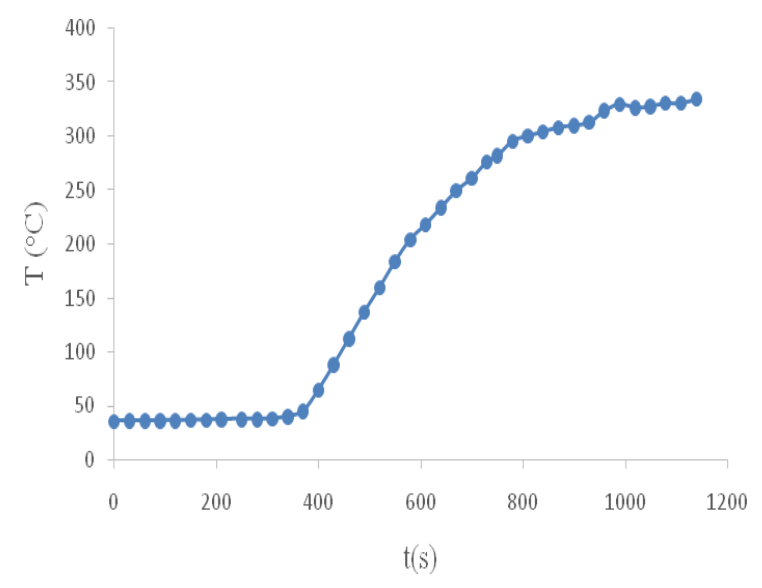

Gambar 6 Grafik hasil pengujian laju pemanasan elemen pemanas

Grafik diatas menunjukkan bahwa laju kenaikan temperatur elemen pemanas sangat kecil atau dapat dikatakan konstan sebelum mencapai laju pemanasan maksimum. Nilai temperatur maksimum yang dapat dihasilkan elemen pemanas hanya sebesar $334{ }^{\circ} \mathrm{C}$.

\subsection{Hasil pengujian laju perubahan temperatur sistem}

Pengujian rangkaian driver dilakukan untuk melihat apakah rangkaian dapat bekerja sesuai dengan input digital dari program. Berdasarkan hasil pengujian diperoleh nilai arus terukur pada rangkaian sebesar $0,16 \mathrm{~mA}$ pada saat input digital low dan elemen pemanas off. Sedangkan pada saat input digital high arus naik menjadi 2,73 mA sehingga elemen pemanas on.

\subsection{Hasil pengujian laju perubahan temperatur sistem}

Pengujian ini dilakukan untuk melihat laju perubahan temperatur yang dihasilkan elemen pemanas di dalam sistem alat yang telah dirancang. Laju temperatur menyatakan waktu yang dibutuhkan elemen untuk menaikkan atau menurunkan temperatur tiap satuan waktu. Pengujian dilakukan langsung pada alat heat treatment kemudian data ditampilkan pada LCD. Hasil pengujian laju kenaikan temperatur dapat dilihat pada Gambar 7(a) dan laju penurunan temperatur dapat dilihat pada Gambar 7(b).

Dari hasil pengujian laju kenaikan temperatur sistem didapatkan bahwa kenaikan temperatur melambat ketika sudah mendekati temperatur maksimum. Temperatur maksimum di dalam sistem hanya mencapai $188{ }^{\circ} \mathrm{C}$ sedangkan pada pengujian elemen pemanas temperatur mencapai $334{ }^{\circ} \mathrm{C}$. Penurunan temperatur kemungkinan dikarenakan elemen pemanas berada di luar sistem sehingga pemanasan tidak terpusat. Hal ini diakibatkan adanya pengaruh temperatur dari lingkungan dan adanya energi panas yang terbuang. Laju penurunan temperatur sistem dimulai setelah elemen pemanas dimatikan. Hasil pengujian laju penurunan temperatur sistem dapat dilihat pada Gambar 7(b). Hasil pengujian laju penurunan temperatur sistem menunjukkan bahwa penurunan temperatur semakin melambat setelah mendekati temperatur ruang. 


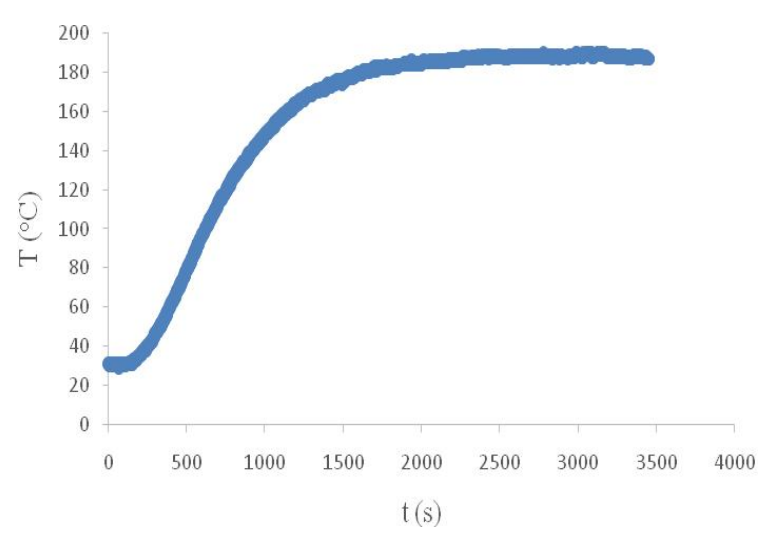

(a)

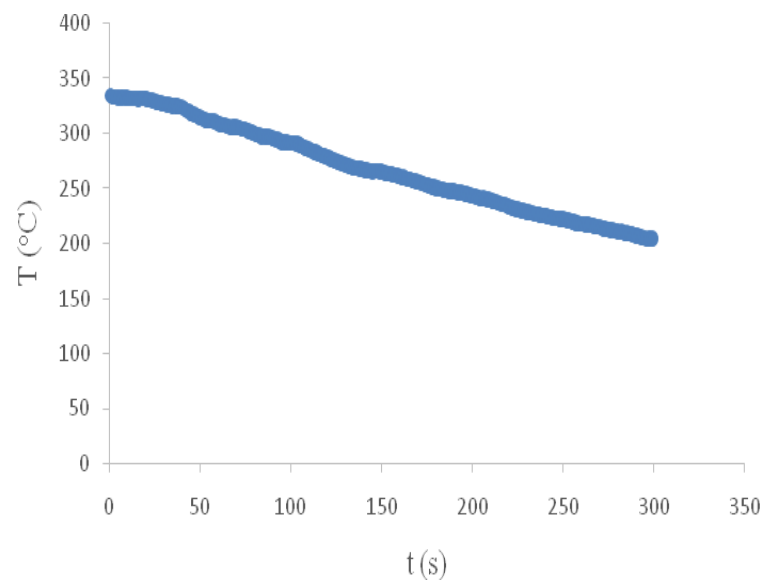

(b)

Gambar 7 (a) Grafik hasil pengujian laju kenaikan temperatur sistem (b) Grafik hasil pengujian laju penurunan temperatur sistem

\subsection{Pengujian sistem kerja alat keseluruhan}

Pengujian alat heat treatment keseluruhan dilakukan untuk melihat apakah sistem kontrol temperatur dan waktu pada alat telah bekerja dengan baik dan tujuan penelitian tercapai. Pengujian dimulai dari pengaturan input temperatur dan input waktu (holding time) dengan menggunakan keypad. Input waktu dimasukkan dengan format hh:mm:ss (jam: menit: detik). Alat akan mulai bekerja setelah pengaturan input selesai, pemanas akan aktif sampai temperatur input tercapai dan temperatur tersebut ditahan sesuai holding time.

Sistem kontrol temperatur dan waktu untuk heat treatment secara keseluruhan dapat berjalan sesuai dengan pengaturan dari user, namun masih terdapat error setpoint. Error terjadi ketika sistem pemanas sudah dimatikan tetapi masih terjadi kenaikan temperatur pada sistem. Temperatur yang terus naik akan berpengaruh terhadap hasil pengujian suatu material. Hal ini dapat diatasi dengan penggunaan elemen termoelektrik maupun pendingin sehingga temperatur sistem dapat diturunkan agar stabil selama waktu tahan. Temperatur maksimal yang dapat diatur pada sistem adalah sebesar $188^{\circ} \mathrm{C}$. Waktu tahan maksimum yang dapat diatur sampai 5 jam.

\section{KESIMPULAN}

Berdasarkan analisis data yang telah dilakukan dapat dikemukakan hasil dari penelitian. Tegangan keluaran sensor termokopel tipe-k sebanding dengan kenaikan temperatur dengan sensitivitas $0,041 \mathrm{mV} /{ }^{\circ} \mathrm{C}$. Laju perubahan temperatur pada elemen pemanas berdaya 400 watt dengan tegangan AC $220 \mathrm{~V}_{\mathrm{AC}}$ dan diukur langsung dengan sensor termokopel mencapai $334{ }^{\circ} \mathrm{C}$. Sistem pengontrolan temperatur dan waktu untuk heat treatment hanya mampu bekerja pada rentang mulai dari temperatur kamar sampai $188{ }^{\circ} \mathrm{C}$ dan holding time maksimum 5 jam. 
Semakin tinggi temperatur sistem dan mendekati nilai maksimum maka laju pemanasan akan semakin lambat begitupun sebaliknya pada saat sistem dimatikan dan semakin mendekati temperatur ruang maka laju penurunan temperatur juga akan semakin lambat.

\section{DAFTAR PUSTAKA}

Kurniawan, B. E., Yuli, S., 2014, Pengaruh Vasiasi Holding Time pada Perlakuan Panas Quench Annealing terhadap Sifat Mekanik dan Mikro Struktur pada Baja Mangan AISI 3401, Jurnal Teknik POMITS, Vol. 3, No. 1, Hal. 113- 116.

Kingsley, U. O., Silas, A. U., Samson, I. A., Oluwafemi, O. A., Adgidzi, D., Raymond, R., Olunsule, S. O. O., "Development of Low Heat Treatment Furnace" (International Journal of Applied Science and Technology, Vol. 2, No. 7, 2012), Hal. 188-194.

Raharjo,W. P., Kusharjanta, B., "Rancang Bangun Pemanas Induksi Berkapasitas 600 W untuk Proses Perlakuan Panas dan Perlakuka Permukaan", Prosiding SNST ke-4, Fakultas Teknik. Universitas Wahid Hasyim, Semarang, 2013.

Suari, M., "Perancangan Sistem Pewaktuan dan Pengontrolan Temperatur pada Aplikasi Kamar Temperatur dengan Sensor LM35DZ Berbasis Mikrokontroler AT89S52" (Jurnal Ilmu Fisika (JIF) Vol. 4, No. 2, 2011), Hal. 67-75.

Suprastiyo, H., Tjahjanti, P., "Pembuatan Electric Furnace Berbasis Mikrokontroler", REM Jurnal, Vol. 1, No. 2, 2016, Hal. 37-42 